\title{
Why rapid, adaptive evolution matters for community dynamics
}

\author{
Hanna Koch ${ }^{\dagger}$, Jens Frickel ${ }^{\dagger}$, Martha Valiadi and Lutz Becks* \\ Community Dynamics, Department of Evolutionary Ecology, Max Planck Institute for Evolutionary Biology, Plön, Germany
}

Edited by:

Shiang-Lin Huang, National Taiwan

Ocean University, Taiwan

Reviewed by:

Cang Hui, Stellenbosch University,

South Africa

David Alonso, Consejo Superior de

Investigaciones Cientificas, Spain

Emanuel A. Fronhofer, Eawag:

Swiss Federal Institute of Aquatic

Science and Technology, Switzerland

Mingli Lin, Chinese Academy of

Sciences, China

\section{${ }^{*}$ Correspondence}

Lutz Becks, Department of

Evolutionary Ecology, Max Planck

Institute for Evolutionary Biology,

August-Thienemann-Str. 2, 24306

Plön, Germany

e-mail: Ibecks@evolbio.mpg.de

tThese authors have contributed

equally to this work.
Evolution on contemporary timescales has recently been recognized as an important driver for ecological change. It is now well established that evolutionary change can affect the interactions between species within a few generations and that ecological interactions may influence the outcome of evolution in return. This tight link between ecology and evolution is of fundamental importance as it can determine the stability of populations and communities, as well as the generation and maintenance of diversity within and among populations. Although these eco-evolutionary dynamics and feedbacks have now been demonstrated many times, we are still far away from understanding how often they occur in nature. We summarize recent findings on eco-evolutionary dynamics, with a focus on consumer-resource interactions, from theory and empirical research. We identify gaps in our knowledge and suggest future research directions to provide a mechanistic understanding and predictive capability for community and ecosystem responses to environmental change.

Keywords: eco-evolutionary dynamics, eco-evolutionary feedback, rapid evolution, species interaction, consumer-resource

\section{INTRODUCTION}

Since the realization that evolutionary processes can be relatively fast, the traditional notion to consider evolutionary biology and ecology as two independent fields has changed dramatically. Although it is known that ecological change can drive evolutionary processes through natural selection, the interplay of ecology and evolution as a dynamic interaction in both directions and on contemporary timescales, has only recently been considered. In ecology, populations are usually considered to be genetically homogeneous and without variation in traits. Evolutionary processes are traditionally considered to be too slow to interact directly with ecological change. Initial theoretical models predicted the potential of rapid evolution to drive the entanglement of evolutionary and ecological dynamics (Abrams and Matsuda, 1997). Now, increasingly more studies underline the idea that populations can exhibit substantial genetic variation in traits that affect population dynamics (Tessier et al., 2000; Lankau and Strauss, 2007; Franks and Weis, 2008; Johnson, 2011; Yang et al., 2012; Novy et al., 2013), and population dynamics can alter the strength and direction of selection within a few generations (Yoshida et al., 2003; Becks et al., 2010, 2012). This confirms the paradigm that demographic and evolutionary changes are ultimately entangled (Ford, 1949; Pimentel, 1961, 1968).

The importance of this tight interaction between ecological and evolutionary change on one timescale has been emphasized in several studies and recent review articles (Fussmann et al., 2007; Pelletier et al., 2009), which has also been named the "newest synthesis" (Schoener, 2011). However, we currently cannot tell how changes in this interaction affect our ability to predict ecological and evolutionary trajectories. Are there ecological processes that are more likely to be affected by evolution within a few generations? And in return, are there ecological processes and species interactions that are more likely to promote rapid evolution? How widespread is the occurrence of a continuous feedback between ecological and evolutionary change? At present we simply do not know. We argue here that a key requirement to answer these questions is to account for higher complexity with more biotic interactions and different agents of selection. Integrating community ecology into the framework of eco-evolutionary dynamics and vice versa allows accounting for time-lagged and cascading effects across different trophic levels. We use simple consumerresource systems here for explaining the conceptual framework of rapid evolution and eco-evolutionary dynamics before we discuss examples and consequences for more complex systems and dynamics.

\section{CONCEPTUAL FRAMEWORK}

We use the term rapid evolution to describe changes in heritable trait distribution or allele frequency within a population over a few generations (c.f. microevolution). This trait variation may arise from the emergence of novel genotypes, gene flow and genetic mixing. Our definition of rapid evolution also includes selection on standing genetic variation in populations. Many of the best examples of rapid evolution are indeed from populations with standing genetic variation, where populations can rapidly evolve by changing genotype frequencies (lineage sorting) 
or by genetic mixing (Turcotte et al., 2011; Agrawal et al., 2012; Cameron et al., 2013). With this definition, we are less strict than those used by other authors. Thompson (1998) and Hairston et al. (2005) define rapid evolution as a process that simultaneously alters the ecological trajectory; however, this definition makes the strong assumption that changes of the ecological dynamics can be observed. Rapid evolutionary change can, however, also result in simply maintaining a status quo by sustained directional selection (Merilä et al., 2001).

Much of our mechanistic understanding of eco-evolutionary dynamics is based on predator-prey systems comprising microbial organisms. These enable multi-generational experiments in the laboratory that can be directly compared to predictions made by theoretical models. As an example of how rapid evolution and ecological dynamics are entangled, we compare trait and population dynamics of a model predator-prey system. Theoretical and empirical literature on the ecology of predator-prey interactions is vast and these systems are the best-studied examples for the tight link between ecological and evolutionary dynamics on one timescale (Abrams and Matsuda, 1997; Reznick et al., 2001; Yoshida et al., 2003; Becks et al., 2010, 2012). In classic ecological predator-prey systems, the entire process of death and birth is solely driven by the densities of the prey and predator, which result in standard ecological one-quarter lag predator-prey cycles (Figure 1A). However, when the prey population exhibits diversity - whether from de novo mutation, gene flow or standing genetic variation - within traits that affect its susceptibility to predation, the prey population can evolve rapidly in response. This rapid evolutionary response can have major effects on the ecological dynamics of the predator-prey system and result in a number of different types of dynamics, including steady state, chaos, or limit cycles. In these cases, it is not only the densities of predators and prey that drive the system dynamics, but also the changes in trait distributions that directly affect birth and death rates (Figure 1B). These eco-evolutionary dynamics, with a tight link between ecological and rapid evolutionary change, are often complex and interactions can go into both directions (Table 1): rapid evolution affecting ecological dynamics, or ecological change affecting rapid evolution.

In some cases, eco-evolutionary dynamics can result in a loop where ecological and evolutionary change continuously feedback into each other and produce for example almost out-of-phase predator-prey population cycles (Figure 1C). This means that there is a continuous change in the importance of predator and prey densities (ecology) and of the trait distributions (evolution) affecting birth and death of predator and prey. These ecoevolutionary feedbacks are a distinct subset of eco-evolutionary dynamics in that they specifically refer to reciprocally interacting ecological and evolutionary processes (Palkovacs and Post, 2008; Post and Palkovacs, 2009), rather than simply considering the effects of ecology on evolution, or less often, the effects of evolution on ecology. Eco-evolutionary feedbacks are characterized by fluctuating selection which leads to oscillating population densities as different traits are favored at different time points (Figure 1C). This maintains trait variation and can allow the diversity of organisms that bear these traits to persist. Thus, one of the most important consequences of eco-evolutionary feedbacks is that the alteration of population and community dynamics results in the maintenance of diversity.

In this review, we discuss examples that document how, together, rapid evolution and ecological change result in ecoevolutionary feedbacks or dynamics, and what implications these feedbacks have on communities. We summarize recent findings from field studies, experiments and theory with the aim to identify processes where the close interaction between ecological and evolutionary dynamics can, within a few generations, play a major role in determining the ecological and evolutionary trajectories. We focus on recent research involving consumer-resource interactions to identify important next steps that could help reveal the conditions under which the tight link between rapid evolutionary change and ecological dynamics matters for the stability and persistence of communities, as well as for the maintenance of diversity.

\section{CONSUMER-RESOURCE INTERACTIONS}

Eco-evolutionary feedbacks have been primarily investigated in predator-prey communities, since the strong selection exerted by predation drives evolution rapidly enough to enable synchrony of evolutionary and ecological dynamics (Abrams, 2000). Abrams and Matsuda (1997) used a model to show that when a prey species evolves a defended genotype at a cost of a lower growth rate, classic predator-prey dynamics exhibiting a typical quarterphase lag (Figure 1A) are shifted toward longer cycles, where predator and total prey cycle out of phase (Figure 1C). These out-of-phase cycles are indicative of eco-evolutionary feedbacks and were first highlighted experimentally by Yoshida et al. (2003) using plankton communities comprising the alga Chlorella vulgaris and the rotifer Brachionus calyciflorus. The algal population consisted of several genotypes differing in their degree of edibility, with a trade-off of lower growth rate for increased defense (Yoshida et al., 2004). These dynamics have also been observed, but in more detail, in a community with Chlamydomonas reinhardtii and the same rotifer species (Jones et al., 2009; Becks et al., 2010, 2012). Key to this system is that the algal prey population consists of genetically variable individuals (Valiadi and Becks unpublished data) with a trade-off between defense against rotifer predation (by growing in colonies) and competitive ability for nutrients. Rapid evolution within the prey population, as a response to predation (i.e., changes in the frequencies of defended and undefended prey type), determines the dynamics of the predator-prey system and whether or not the polymorphism of defended and undefended prey types is maintained. These experiments confirmed the predictions of a mathematical model (Figure 2) where the prey (algae) evolves a defense when predation is intense but loses this defense (and gains competitive ability) when the predators (rotifers) are scarce and prey are abundant (Figures 2B,D). Rapid evolution of the prey results in sustained oscillations of the community and trait dynamics, as well as the maintenance of the initial trait diversity.

Eco-evolutionary feedbacks in predator-prey systems can give rise to a number of different types of dynamics depending on food web complexity, the efficiency, and cost of prey defense (Yoshida et al., 2007; Jones et al., 2009; Tien and Ellner, 2012), and the amount of functional variation initially present in the system 

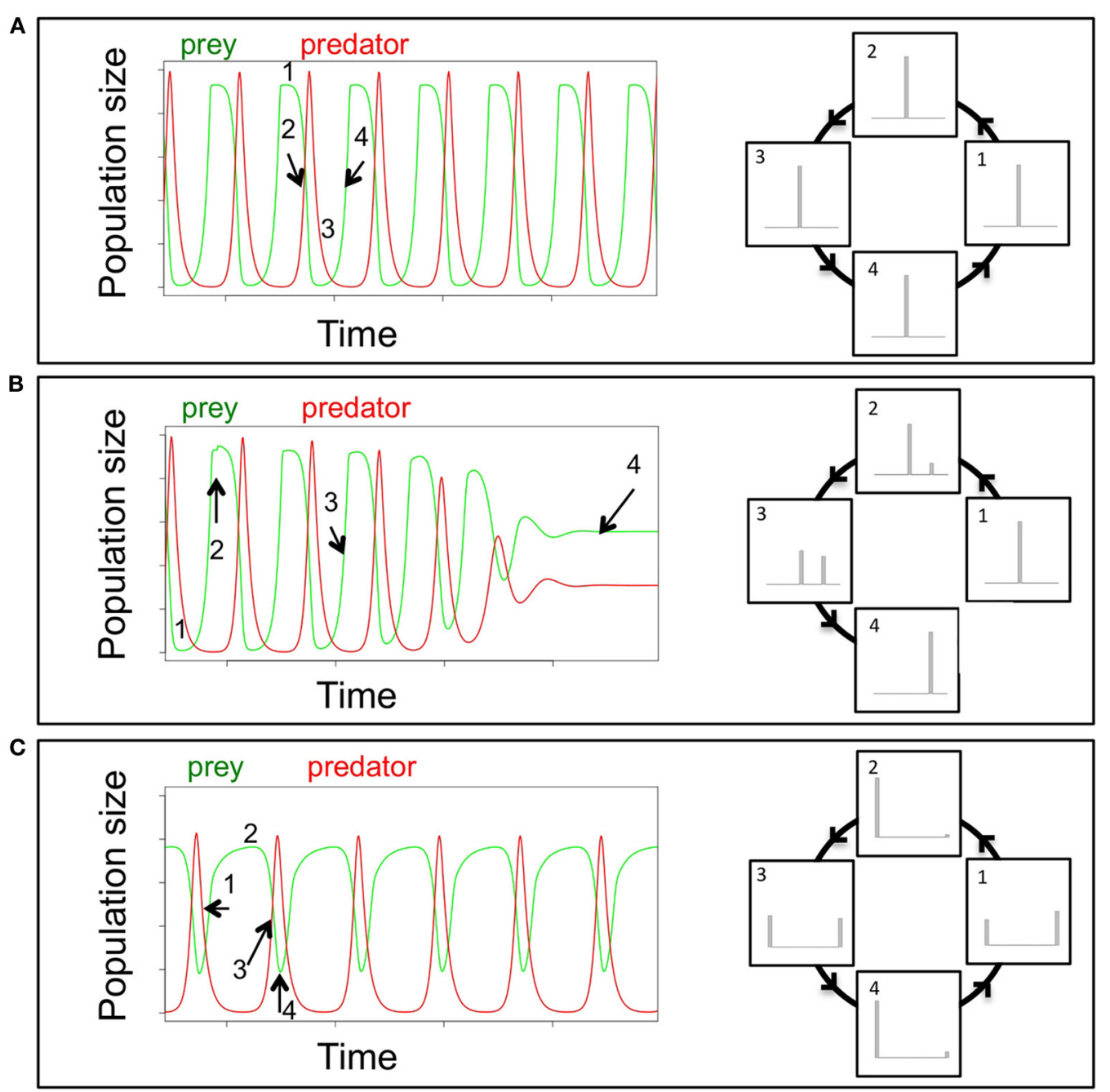

FIGURE 1 | Conceptual framework for the effects of rapid evolution on the quantitative dynamical behavior of a predator-prey system shown as population dynamics (left) and the corresponding trait distribution of a defense against the predator within the prey population (right).

(A) For a cyclical predator-prey system without evolution, the predator and prey cycle with a phase shift of a quarter of a period. High prey densities (time point 1) lead to growth of the predator population, which

simultaneously results in high death rates of the prey and decreasing prey densities (time point 2). As an outcome of low prey densities, the predator populations' growth rate becomes negative (time point 3 ) and the resulting low density of the predator allows the prey population to rapidly grow again, as long as the predator population stays low (time point 4). As the classical ecology case does not consider evolution and trait variation, the trait distribution does not change over time with changes in prey and predator densities (numbers in left and right columns are corresponding time points). (B) The introduction of trait variation in the prey population by the emergence of a new prey type that is defended against predation stabilizes the dynamics from cycles to steady state dynamics. Introduction of a new phenotype in the prey population, either through de novo evolution or gene flow that, for example, reduces consumption by the predator (i.e., a "defended" prey), could result in a change of the quantitative dynamics of the system. A newly introduced defended prey type has (time point 2), in the presence of the predator, a lower death rate compared to the undefended prey and its frequency increases over time through several predator-prey cycles (time point 3). Increasing defended prey results in less efficient predation as well as reduced growth and population sizes of the predator and the undefended prey goes extinct and the predator-prey dynamics switch to steady state dynamics (time point 4). Thus, the evolution in the prey population, shown as trait distribution in the right column of Figure 1B, has a direct effect on the ecological dynamics of predator and prey. (C) For the case where the defense level against predation is very efficient but comes at a cost of a low competitive ability, a full eco-evolutionary feedback can be observed. The growth rates of the two prey types then depend on the density of the prey, while the density of the predator and its ability to feed on the two different preys determines the preys' death rates. The relative impact of the two processes continuously changes, driven by the changes in prey and predator densities, which in turn are driven by changing frequencies of the two prey types. Here, low rotifer densities select for undefended prey (time point 2), which in return results in an increase in predator densities (time point 3). With high predator densities, the defended prey increases in frequency, driving the predator to low densities again (time point 4). As a result, the overall dynamics of the predator-prey system differs drastically from classical predator-prey dynamics: the system cycles, but cycles are much longer than classic consumer-resource cycles (Figure 1A) and almost out of phase. This represents a full eco-evolutionary feedback loop where evolutionary change (changes in the trait distribution, right column

Figure 1C) affects the ecological dynamics (density of the predator), which in return drives the evolutionary change (the circle in the right column is closed) (Palkovacs and Post, 2008; Post and Palkovacs, 2009). 
Table 1 | Sample of recent (2010-2014) studies on eco-evolutionary dynamics.

\begin{tabular}{llll}
\hline References & $\begin{array}{l}\text { Level of } \\
\text { organization }\end{array}$ & Type of study & Type of interaction/ecological driver Organism(s)
\end{tabular}

\section{ECOLOGY DRIVES RAPID EVOLUTION}

Agrawal et al., 2012

Burton et al., 2010

Community

Kelehear et al., 2012

Community

Community

Population

Swain, 2011

Thériault et al., 2011

Population

Community

Turley et al., 2013

\section{RAPID EVOLUTION DRIVES ECOLOGY}

Community

Bassar et al. 2010

Cameron et al., 2013

Ecosystem

Population

Coulson et al., 2011

Population

Friman et al., 2014

Community

Hairston et al., 2005;

Ellner et al., 2011

Population,

Community

Terhorst et al., 2010

Community

Population

Turcotte et al., 2011

Walsh et al., 2012

Ecosystem

\section{ECO-EVOLUTIONARY FEEDBACKS}

Becks et al., 2010, 2012 Community

Ellner and Becks, 2011 Community

Community

Farkas et al., 2013

Hanski, 2011

Sanchez and Gore,

2013

Turcotte et al., $2011 \quad$ Population

Yamamichi et al., 2011
Experiment

Experiment

Theory and Field

data

Experiment (field
manipulation)
Theory
Experiment

Experiment (long-term study)

Theory

Experiment (long-term, field manipulation)

Field experiment

Plant-herbivore

Three-trait trade-off model, range expansion, biological invasion Host-parasite, range expansion

Over-harvesting, exploitation

Eco-genetic modeling, fisheries-induced rapid evolution Plant-herbivore

Experiment

Theory

Theory

Experiment

Experiment

Experiment
Predator-prey

Predator-prey and ecosystem structure and function Rapid evolution driven by density-dependent competition Environmental change on life history and population dynamics Predator-prey and competition Predator-prey, environmental change

Rapid evolution on population growth Predator-prey and ecosystem function

\author{
Common evening primrose \\ (Oenothera biennis), Insects \\ Model species
}

Nematode lungworm (Rhabdias pseudosphaerocephala), Cane toad (Rhinella marina)

Fish (e.g., Atlantic cod, Gadus morhua)

Brook charr (Salvelinus fontinalis)

Sorrel plant (Rumex acetosa), Common rabbit (Oryctolagus cuniculus)

Evening primrose (Oenothera biennis), Seed predator moth (Mompha brevivittella)

Trinidadian guppies (Poecilia reticulata)

Soil mite (Sancassania berlesei)

Wolf (Canis lupus)

Bacteria (Pseudomonas fluorescens), Protist (Tetrahymena thermophile) Theoretical (based on Abrams and Matsuda), Medium ground finch (Geospiza fortis), Freshwater copepod (Onychodiaptomus sanguineus) Mosquito larvae (Wyeomyia smithii), Protozoa (Colpoda sp.)

Green peach aphid (Myzus persicae) Zooplankton (Daphnia dentifera), Phytoplankton community

Chlorophyte alga (Chlamydomonas reinhardtii), Rotifer (Brachionus calyciflorus)

Based on chlorophyte alga (Chlamydomonas reinhardtii), Rotifer (Brachionus calyciflorus)

Stick insect (Timema cristinae), Plants (Adenostoma fasciculatum,

Ceanothus spinosus)

Glanville fritillary butterfly (Melitaea cinxia)

Microbial yeast, Saccharomyces cerevisiae

Green peach aphid (Myzus persicae)

Inspired by chlorophyte alga (Scenedesmus and Desmodesmus), Rotifers 
A

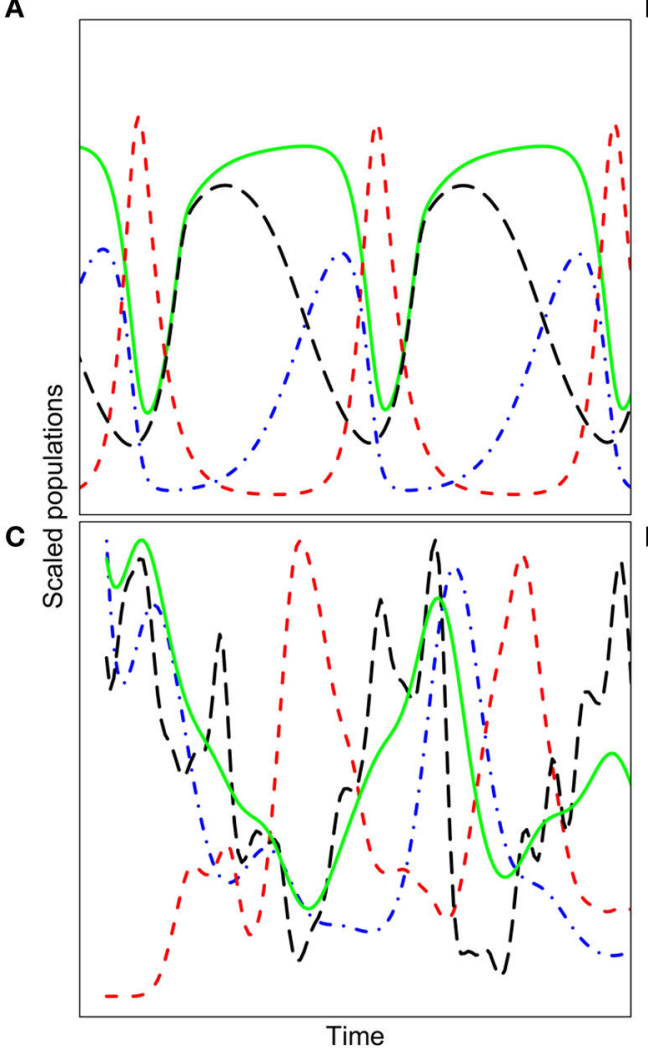

B

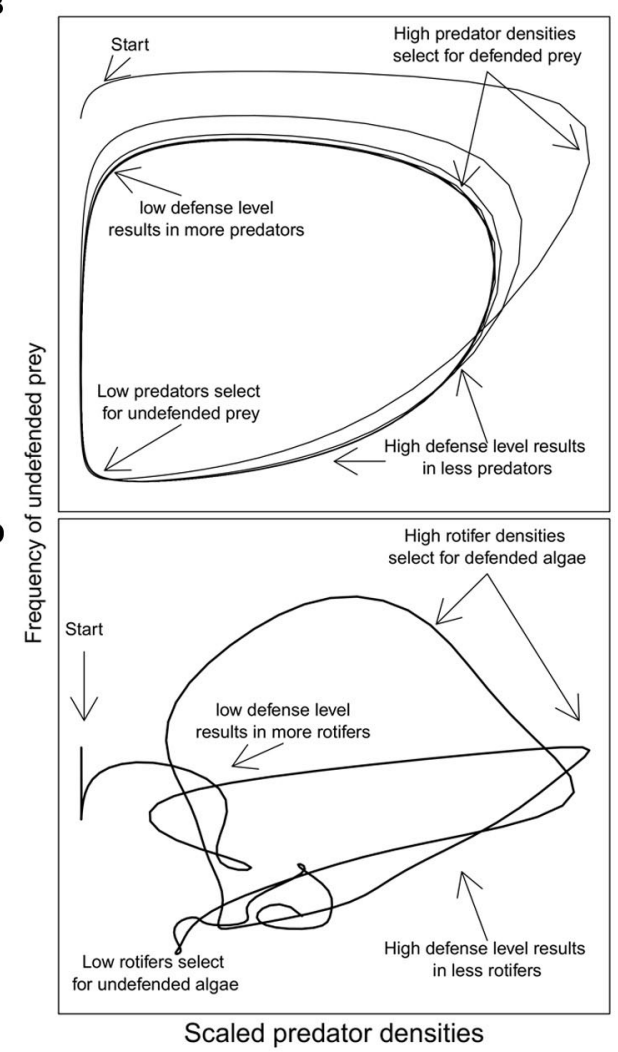

FIGURE 2 | Details of eco-evolutionary feedback dynamics in a predator-prey system from model predictions and experiments (after Becks et al., 2010, 2012). (A) Scaled population sizes of the predator, the total prey, defended, and undefended prey; total prey: solid green line, red dashed line: predator, blue long-dashed line: undefended prey, black dash-dotted line: defended prey. (B) Frequency of the undefended prey as a function of predator densities and the major ecological and evolutionary drivers at different time points. The inevitable lag in response to selection and changes in population densities create then the long out of phase cycles. (C,D) are experimental data from a rotifer-algae system. For visualization reasons, only the fitted lines are shown.
(Becks et al., 2010). Yoshida et al. (2007) used algae-rotifer and bacteria-phage communities to demonstrate how cryptic cycles can occur when there is rapid evolution in prey defense traits, but the cost of this defense is not high enough to force significant competition among prey genotypes. Instead of observing population cycles in both the predator and prey, only the predator cycled while the algal population appeared to remain constant. This was because the rapid evolutionary cycling of prey genotypes within the population allowed for essentially constant total prey number, even while the predator population fluctuated. Again, this allows trait variation in the prey population to be maintained. Conversely, low levels of prey defense result in steady state dynamics instead of an eco-evolutionary feedback, because in this case, effective defense drives the predator to low levels, but not low enough to allow coexistence of the undefended prey type (Jones et al., 2009). As a consequence of the steady-state dynamics between the predator and prey, prey diversity is not maintained.

Studies of consumer-resource systems considering rapid evolution in both the predator and prey have revealed more complex evolutionary and population dynamics than those only considering rapid evolution in the prey populations (Jones et al., 2009;
Tirok et al., 2011). A most striking outcome is that time periods of cycling predator and prey alternate with time periods of intermittency. Important to this dynamic is that during the latter time periods, trait variation is maintained and the next burst of cycles is not the result of new mutations, but rather of temporal changes in the dominance of different prey and predator types. Similar complex eco-evolutionary feedbacks were observed in a predatorprey food chain that was extended to include an intermediate predator (Ellner and Becks, 2011). Allowing for evolution of a costly defense against neither, one or both predators, the authors found that the increased number of interactions did not mask, but rather accentuated the eco-evolutionary dynamics. Long out-ofphase cycles and even chaotic dynamics were observed; with both resulting in the maintenance of the initial diversity in prey defense traits. Many studies have discovered rapid, adaptive evolution in prey populations exposed to novel or increased predation but they usually do not follow the consequences for predator-prey dynamics or potential for a full eco-evolutionary feedback. For example, a protozoan prey evolved a defense against predation by mosquito larvae by growing faster but to a smaller cell size, resulting in a change in the predator effect size within a few generations 
(Terhorst et al., 2010). In this study, the reduced effect size of the predator does consequently change the predator's grazing rate and thus the strength of selection. However, whether this might change the direction of selection (from prey being defended to being competitive) and consequently change the evolutionary trajectory was not tested.

These examples emphasize the significance of rapid evolution and eco-evolutionary feedbacks in consumer-resource systems, within the context of community alterations, like invasions and expansions (Facon et al., 2006; Kinnison and Hairston, 2007; Burton et al., 2010; Jones and Gomulkiewicz, 2012). They also illustrate that the relative importance of variation within and among different traits might differ over time depending on the ecological dynamics. It is this dynamic, reciprocal, and often time-lagged cascading interaction between the ecological and evolutionary processes that makes its understanding so challenging.

\section{NATURAL COMMUNITIES}

The great challenge now facing evolutionary ecologists is to apply what we have shown by models and laboratory experiments to the natural world. This is far from trivial in complex ecosystems, especially considering that the same dynamics are often a result of very different processes. The main findings from the rotifer-algae chemostat systems, i.e., that genetic variation can alter ecological dynamics, have now been corroborated by field and mesocosm studies using the Trinidadian guppy Poecilia reticulata. In this model system, varying levels of predation underlie the rapid evolution of morphological (e.g., body size), life history (e.g., age at sexual maturity), and behavioral (e.g., anti-predator) traits in the prey (Magurran et al., 1992; Reznick et al., 1996, 1997, 2001; Kemp et al., 2009). In addition to linking the rapid evolutionary change with the varying levels of predation, it has been shown that the differentially adapted guppies make different use of resources, which can have cascading effects throughout the entire ecosystem. For example, Bassar et al. (Bassar et al., 2010; Ellner et al., 2011) found that guppy evolution indirectly affects decomposition rates and levels of benthic organic matter, while other ecosystem processes such as gross primary production and total nitrogen flux were only affected by ecological changes (i.e., intraspecific density). Similar results were obtained in another mesocosm study using the stickleback Gasterosteus aculeatus, to test for divergent effects on ecosystem function by fish with differentially-adapted foraging strategies (Harmon et al., 2009). Diversification into specialized benthic and limnetic feeders had profound effects on algae biomass and productivity by creating a positive feedback between dissolved organic carbon and algal productivity. Both studies showed the consequences of rapid evolution for several, often cascading, ecological and ecosystem processes. However, they do not allow for making further predictions on how ecological and evolutionary dynamics might change after the initial/short-term effect (in both cases, the mesocosm experiments lasted less than one fish generation). It is this long-term effect and the potential feedback that should be of our utmost interest for future studies as it can have far-reaching consequences for community dynamics and genetic diversity.
A series of studies comparing lakes with either landlocked or anadromous alewife (Alosa pseudoharengus) populations show how the ecological and evolutionary dynamics of communities and ecosystems might be dramatically altered by an initial ecological change. Landlocked alewives exert a constantly high grazing pressure on the zooplankton population throughout the year. Over time, the zooplankton population in these lakes evolved to be smaller and grow slower (Palkovacs and Post, 2008; Post et al., 2008; Walsh and Post, 2011). The changes in zooplankton had further evolutionary consequences for the alewives as they are suggested to have rapidly evolved smaller gape width and gillraker spacing (Palkovacs et al., 2008; Palkovacs and Post, 2009). At the same time, these modifications in zooplankton and alewife populations increased phytoplankton biomass and lowered net primary production (Post et al., 2008; Walsh et al., 2012). A lower net primary production could have a large effect on ecosystem structure and energy flow; and could also, in theory, lead to a full eco-evolutionary feedback on the zooplankton dynamics. Conversely, anadromous alewife populations do not exert a constantly high grazing pressure throughout the year and thus, have not undergone the same evolutionary and ecological changes as the landlocked alewife populations.

The experimental systems discussed here reveal the difficulties and limitations in performing these types of studies in natural populations, where interactions may be masked, amplified or just be difficult to disentangle from a range of other ecosystem processes (see also Strauss, 2014). In addition, the above-described cascading effects across different trophic levels will need several generations despite rapid evolution. At the same time, these studies also demonstrate the pressing need to understand these often simultaneous and intertwined ecological and evolutionary dynamics. For example, primary production in lakes is of high interest, i.e., its importance for carbon sequestration, inland fisheries, community shifts to favor harmful algal blooms, and the sustainability of drinking water reservoirs.

\section{SO WHAT?}

We propose that to fully understand eco-evolutionary dynamics and feedbacks in communities, it is essential to quantify the ecological and evolutionary dynamics, including the heritability of the traits involved and their effects on species interactions, e.g., level of defense, competitive ability or susceptibility, and resistance. Most studies, so far, have focused on single or twospecies systems and typically one evolving trait. Studies including more interacting species (Ellner and Becks, 2011) or evolving traits (Burton et al., 2010) illustrate that the potential for ecoevolutionary feedbacks does not diminish when including more complexity (Urban et al., 2008; Tirok and Gaedke, 2010; Tirok et al., 2011). There is also a need to identify traits that are most likely to evolve rapidly and affect ecological interactions (Geber and Griffen, 2003; Thompson, 2009). In addition, little is known about how the rate of evolutionary change depends on the strength of selection and how selection strength alters the potential and shape of eco-evolutionary dynamics. This might be particularly interesting for the conditions leading to a feedback. With increasing number and types of interactions, the direction and strength of selection will change and the resulting dynamics 
will be limited by intrinsic evolutionary (Burton et al., 2010; Schiffers et al., 2013) and energetic constraints (Wirtz, 2011). In addition, more work is needed on the consequences of indirectly selected traits (Walsh, 2012). This requires integrating population genetic models and theory into the framework of rapid evolution to facilitate a quantitative understanding of the general mechanisms underlying rates of evolution, how trade-offs evolve and how this shapes eco-evolutionary feedbacks.

Eco-evolutionary dynamics and feedbacks are of high importance for many other ecological and evolutionary processes and should thus be integrated into theory and studies in the fields. One such field in particular that has already gained much attention and begun to incorporate rapid evolution and/or ecoevolutionary dynamics into their studies on the evolution of life-history traits is overharvesting, e.g., fisheries-induced evolution (Conover and Munch, 2002; Swain, 2011; Thériault et al., 2011). However, there are still a number of research fields that have, so far, neglected rapid evolution but should directly benefit from integrating eco-evolutionary dynamics. Rapid evolution is, for example, rarely considered in population genetic theory and analysis, although rapid evolution and its simultaneous interaction with ecological dynamics can have dramatic effects on the strength and direction of selection. Overlooked, so far, in the field of population genetics is that these changes in strength and direction of selection are fast, i.e., within a few generations. The field of population genetics usually assumes large and constant population sizes. However, as previously discussed, the simultaneous occurrence of evolutionary and ecological change on one time scale typically results in fluctuations of population sizes by several orders of magnitude. As an example, the direction and strength of selection on a prey population changes with predator densities; high grazing pressure selects for defense against grazing, while times of low grazing pressure select for increased competitive abilities among the prey (Figure 1). The general underlying population genetic mechanisms, and perhaps more importantly, the consequences for our thinking of population genetics and analysis, are still unknown. At the same time, it is likely that by including population genetics into the studies of eco-evolutionary dynamics, we will learn more about the mechanisms that create and maintain intraspecific diversity.

Rapid evolution in consumer-resource systems can also play a crucial role during biological invasions and range expansions or shifts (Kubisch et al., 2014). During such events, rapid evolution in response to novel selection pressures can affect the population dynamics, which can, in turn, further feed back on the evolutionary processes. Burton et al. point out that the rate at which a population can spread through space depends on its reproductive rate, density dependence and dispersal ability (Burton et al., 2010); they developed a model to show how, during range expansion, these three traits can trade off against each other. Their simulations revealed that while dispersal and reproduction are selected for on the expanding front of the introduced species, traits associated with fitness at equilibrium density (competitive ability) significantly decline. This changes, however, when considering different types of biotic interactions of introduced species (predator-prey, mutualism, or competition) (Jones and Gomulkiewicz, 2012). In these cases, Jones et al. argue that the establishment of an invading species depends, not only on the interaction type, but also largely upon the genetic variation within the native population, and therefore its potential for an evolutionary response to that invader. While rapid evolution of the invader always facilitates establishment, the success of that establishment is largely affected when allowing for rapid evolution simultaneously in both invading and native populations, and when considering the initial genetic variation within those interacting populations.

Another important research field that could benefit greatly from incorporating rapid evolution is climate change biology. Climate change alters existing species interactions that are embedded within a food web. Ample studies have demonstrated that temperature shifts might result in mismatches in, for example, phenology (Stenseth and Mysterud, 2002; Edwards and Richardson, 2004; Jones and Cresswell, 2010; Ovaskainen et al., 2013) or between consumer and resource (Harrington et al., 1999; O'Connor et al., 2009; Van der Putten et al., 2010; Woodward et al., 2010), and we have already discussed the role rapid evolution can play in altering population and community dynamics. Moya-Laraño et al. (2012) introduce a new framework that allows testing for evolutionary and ecological consequences, and their interactions, in food webs in response to warming. Using individual based models (IBMs) of food webs with trait variation for temperature dependent and independent traits, they found that an increase in temperature could lead to trophic cascades, which eventually results in a higher probability of extinction for some trophic levels. In a recent study Northfield and Ives (2013) analyzed the effects of warming on co-evolutionary dynamics of interacting species. They found that depending on the type of interaction, coevolution could result in feedback loops that might dampen the effects of warming. However, the feedback between ecological and (co)evolutionary change might also result in amplifying the effects of temperature change. In all, the results show how climate change may have profound eco-evolutionary effects, which may also affect the future persistence and functioning of food webs and the community of species that structure them.

\section{CONCLUSION}

Research on eco-evolutionary dynamics and feedbacks has already uncovered their potential complexity and importance in community dynamics, but the field is still in its infancy. Looking at the variety of ways ecological and evolutionary processes are entangled (Table 1), it is plain to see that ecology or evolution cannot be understood in the absence of the other. Our main (not novel) conclusion is that ecological and evolutionary dynamics are intertwined in complex ways. Even when not explicitly shown, rapid evolution almost always has the ability to change community dynamics by altering ecological interactions within these communities. At the same time, community dynamics have a high potential to modify evolutionary trajectories by altering the strength or direction of selection (Figures 1, 2; Table 1). Clearly, eco-evolutionary feedbacks are important as they can maintain diversity within a closed system that is not affected by external ecological processes (Hanski, 2012). This diversity might then serve as a resource for further evolutionary processes, such 
as diversification and speciation. Studies demonstrating rapid evolution are mainly from populations exposed to strong and steady directional selection, e.g., after introducing or removing a predator (e.g., Olsen et al., 2004; Araki and Schmid, 2010), or from systems with fluctuating selection, where species interactions frequently alter the direction of selection (e.g., Duffy and Sivars-Becker, 2007; Palkovacs et al., 2009; Becks et al., 2010, 2012; Turcotte et al., 2011). Spatial dynamics including range expansion and invasion, as well as local adaptation of communities, have also proven to have a large potential for eco-evolutionary dynamics and feedbacks (Reznick et al., 2001; Hanski and Saccheri, 2006; Kerr et al., 2006; Dlugosch and Parker, 2008; Bassar et al., 2010; Kelehear et al., 2012).

Another conclusion that we can draw is that, depending on the assumptions and conditions, every outcome for community dynamics and the direction of adaptive evolution seems to be possible. Integrating multiple interactions into eco-evolutionary feedbacks can result in multiple possible outcomes. This poses a huge challenge for the experimentalist and thus, likely requires an approach with a strong theoretical background. Some theorybased studies predict that rapid evolution does not always play a role (Jones and Gomulkiewicz, 2012) or only plays a role under certain assumptions (e.g., in the form of a trade-off curve Jones and Ellner, 2007; Jones et al., 2009). Therefore, more modeling and theory-driven studies will be necessary to help identify those conditions under which rapid evolution drives further ecological and evolutionary change, in addition to identifying which interactions, besides consumer-resource, are most relevant. These types of studies, including experimental ones, will also be important for better understanding how indirect species interactions facilitate or inhibit cascading effects of eco-evolutionary dynamics and feedbacks. Currently, there is a poor understanding of the consequences of eco-evolutionary dynamics for indirect ecological effects, such as apparent competition or trophic cascades (but see Bassar et al., 2010; Walsh et al., 2012). It is also important to know whether eco-evolutionary feedbacks in nature withhold in the presence of external ecological pressures. Additional experimental studies analysing eco-evolutionary feedbacks and eco-evolutionary dynamics, in general, are needed to critically assess their role in maintaining diversity within and among populations. However, a key requirement for this is that we achieve a better mechanistic understanding of the effects of evolution on ecology. It is, essential for predicting how ecological and evolutionary properties, e.g., stability and dynamics of populations and communities, as well as intra-and interspecific diversity, are maintained. A strong understanding of these processes in nature is imperative since eco-evolutionary feedbacks may be of essence to the maintenance of biodiversity and the potential for further adaptive change.

\section{ACKNOWLEDGMENTS}

This work was supported by an Emmy Noether Grant from the German Research Foundation (DFG) to Lutz Becks (grant BE 4135/3-1).

\section{REFERENCES}

Abrams, P. A. (2000). The evolution of predator-prey interactions: theory and evidence. Annu. Rev. Ecol. Syst. 31, 79-105. doi: 10.1146/annurev.ecolsys.31.1.79
Abrams, P. A., and Matsuda, H. (1997). Prey adaptation as a cause of predator-prey cycles. Evolution 51, 1742-1750. doi: 10.2307/2410997

Agrawal, A. A., Hastings, A. P., Johnson, M. T., Maron, J. L., and Salminen, J.-P. (2012). Insect herbivores drive real-time ecological and evolutionary change in plant populations. Science 338, 113-116. doi: 10.1126/science.1225977

Agrawal, A. A., Johnson, M. T. J., Hastings, A. P., and Maron, J. L. (2013). A field experiment demonstrating plant life-history evolution and its eco-evolutionary feedback to seed predator populations. Am. Nat. 181(Suppl. 1), S35-S45. doi: $10.1086 / 666727$

Araki, H., and Schmid, C. (2010). Is hatchery stocking a help or harm? Evidence, limitations and future directions in ecological and genetic surveys. Aquaculture 308, S2-S11. doi: 10.1016/j.aquaculture.2010.05.036

Bassar, R. D., Marshall, M. C., Lopez-Sepulcre, A., Zandona, E., Auer, S. K., Travis, J., et al. (2010). Local adaptation in Trinidadian guppies alters ecosystem processes. Proc. Natl. Acad. Sci. U.S.A. 107, 3616-3621. doi: 10.1073/pnas.0908023107

Becks, L., Ellner, S. P., Jones, E. L., and Hairston, Jr. N. G. (2012). The functional genomics of an eco-evolutionary feedback loop: linking gene expression, trait evolution, and community dynamics. Ecol. Lett. 15, 492-501. doi: 10.1111/j.1461-0248.2012.01763.x

Becks, L., Ellner, S. P., Jones, L. E., and Hairston, Jr. N. G. (2010). Reduction of adaptive genetic diversity radically alters eco-evolutionary community dynamics. Ecol. Lett. 13, 989-997. doi: 10.1111/j.1461-0248.2010.01490.x

Burton, O. J., Phillips, B. L., and Travis, J. M. J. (2010). Trade-offs and the evolution of life-histories during range expansion. Ecol. Lett. 13, 1210-1220. doi: 10.1111/j.1461-0248.2010.01505.x

Cameron, T. C., O'Sullivan, D., Reynolds, A., Piertney, S. B., and Benton, T. G. (2013). Eco-evolutionary dynamics in response to selection on life-history. Ecol. Lett. 16, 754-763. doi: 10.1111/ele.12107

Conover, D. O., and Munch, S. B. (2002). Sustaining fisheries yields over evolutionary time scales. Science 297, 94-96. doi: 10.1126/science.1074085

Coulson, T., MacNulty, D. R., Stahler, D. R., Vonholdt, B., Wayne, R. K., and Smith, D. W. (2011). Modeling effects of environmental change on wolf population dynamics, trait evolution, and life history. Science 334, 1275-1278. doi: 10.1126/science.1209441

Dlugosch, K. M., and Parker, I. M. (2008). Founding events in species invasions: genetic variation, adaptive evolution, and the role of multiple introductions. Mol. Ecol. 17, 431-449. doi: 10.1111/j.1365-294X.2007.03538.x

Duffy, M. A., and Sivars-Becker, L. (2007). Rapid evolution and ecological hostparasite dynamics. Ecol. Lett. 10, 44-53. doi: 10.1111/j.1461-0248.2006.00995.x

Edwards, M., and Richardson, A. J. (2004). Impact of climate change on marine pelagic phenology and trophic mismatch. Nature 430, 881-884. doi: 10.1038/nature02808

Ellner, S. P., and Becks, L. (2011). Rapid prey evolution in response to two predators. Theor. Ecol. 4, 133-152. doi: 10.1007/s12080-010-0096-7

Ellner, S. P., Geber, M. A., and Hairston, N. G. Jr. (2011). Does rapid evolution matter? Measuring the rate of contemporary evolution and its impacts on ecological dynamics. Ecol. Lett. 14, 603-614. doi: 10.1111/j.1461-0248.2011.01616.x

Facon, B., Genton, B. J., Shykoff, J., Jarne, P., Estoup, A., and David, P. (2006). A general eco-evolutionary framework for understanding bioinvasions. Trends Ecol. Evol. 21, 130-135. doi: 10.1016/j.tree.2005.10.012

Farkas, T. E., Mononen, T., Comeault, A. A., Hanski, I., and Nosil, P. (2013). Evolution of camouflage drives rapid ecological change in an insect community. Curr. Biol. 23, 1835-1843. doi: 10.1016/j.cub.2013.07.067

Ford, E. B. (1949). Mendelism and Evolution. London: Methuen.

Franks, S. J., and Weis, A. E. (2008). A change in climate causes rapid evolution of multiple life-history traits and their interactions in an annual plant. J. Evol. Biol. 21, 1321-1334. doi: 10.1111/j.1420-9101.2008.01566.x

Friman, V. P., Jousset, A., and Buckling, A. (2014). Rapid prey evolution can alter the structure of predator-prey communities. J. Evol. Biol. 27, 374-380. doi: $10.1111 /$ jeb. 12303

Fussmann, G. F., Loreau, M., and Abrams, P. A. (2007). Eco-evolutionary dynamics of communities and ecosystems. Funct. Ecol. 21, 465-477. doi: 10.1111/j.13652435.2007.01275.x

Geber, M. A., and Griffen, L. R. (2003). Inheritance and natural selection on functional traits. Int. J. Plant Sci. 164, S21-S42. doi: 10.1086/368233

Hairston, N. G., Ellner, S. P., Geber, M. A., Yoshida, T., and Fox, J. A. (2005). Rapid evolution and the convergence of ecological and evolutionary time. Ecol. Lett. 8, 1114-1127. doi: 10.1111/j.1461-0248.2005.00812.x 
Hanski, I. (2012). Eco-evolutionary dynamics in a changing world. Ann. N.Y. Acad. Sci. 1249, 1-17. doi: 10.1111/j.1749-6632.2011.06419.x

Hanski, I., and Saccheri, I. (2006). Molecular-level variation affects population growth in a butterfly metapopulation. PLoS Biol. 4:e129. doi: 10.1371/journal.pbio.0040129

Hanski, I. A. (2011). Eco-evolutionary spatial dynamics in the Glanville fritillary butterfly. Proc. Natl. Acad. Sci. U.S.A. 108, 14397-14404. doi: 10.1073/pnas.1110020108

Harmon, L. J., Matthews, B., des Roches, S., Chase, J. M., Shurin, J. B., and Schluter, D. (2009). Evolutionary diversification in stickleback affects ecosystem functioning. Nature 458, 1167-1170. doi: 10.1038/nature07974

Harrington, R., Woiwod, I., and Sparks, T. (1999). Climate change and trophic interactions. Trends Ecol. Evol. 14, 146-150. doi: 10.1016/S0169-5347(99) 01604-3

Johnson, M. T. J. (2011). The contribution of evening primrose (Oenothera biennis) to a modern synthesis of evolutionary ecology. Popul. Ecol. 53, 9-21. doi: 10.1007/s10144-010-0250-5

Jones, E. I., and Gomulkiewicz, R. (2012). Biotic interactions, rapid evolution, and the establishment of introduced species. Am. Nat. 179, E28-E36. doi: $10.1086 / 663678$

Jones, E. L., and Ellner, S. P. (2007). Effects of rapid evolution on predator-prey cycles. J. Math. Biol. 55, 541-573. doi: 10.1007/s00285-007-0094-6

Jones, L. E., Becks, L., Ellner, S. P., Hairston, N. G., Yoshida, T., and Fussmann, G. F. (2009). Rapid contemporary evolution and clonal food web dynamics. Philos. Trans R. Soc. B Biol Sci. 364, 1579-1591. doi: 10.1098/rstb. 2009.0004

Jones, T., and Cresswell, W. (2010). The phenology mismatch hypothesis: are declines of migrant birds linked to uneven global climate change? J. Anim. Ecol. 79, 98-108. doi: 10.1111/j.1365-2656.2009.01610.x

Kelehear, C., Brown, G. P., and Shine, R. (2012). Rapid evolution of parasite life history traits on an expanding range-edge. Ecol. Lett. 15, 329-337. doi: 10.1111/j.1461-0248.2012.01742.x

Kemp, D. J., Reznick, D. N., Grether, G. F., and Endler, J. A. (2009). Predicting the direction of ornament evolution in Trinidadian guppies (Poecilia reticulata). Proc. Biol. Sci. 276, 4335-4343. doi: 10.1098/rspb.2009.1226

Kerr, B., Neuhauser, C., Bohannan, B. J. M., and Dean, A. M. (2006). Local migration promotes competitive restraint in a host-pathogen tragedy of the commons. Nature 442, 75-78. doi: 10.1038/nature04864

Kinnison, M. T., and Hairston, N. G. Jr. (2007). Eco-evolutionary conservation biology: contemporary evolution and the dynamics of persistence. Funct. Ecol. 21, 444-454. doi: 10.1111/j.1365-2435.2007.01278.x

Kubisch, A., Holt, R. D., Poethke, H. J., and Fronhofer, E. A. (2014). Where am I and why? Synthesizing range biology and the eco-evolutionary dynamics of dispersal. Oikos 123, 5-22. doi: 10.1111/j.1600-0706.2013.00706.x

Lankau, R. A., and Strauss, S. Y. (2007). Mutual feedbacks maintain both genetic and species diversity in a plant community. Science 317, 1561-1563. doi: $10.1126 /$ science. 1147455

Magurran, A. E., Seghers, B. H., Carvalho, G. R., and Shaw, P. W. (1992). Behavioural consequences of an artificial introduction of Guppies (Poecilia reticulata) in N. Trinidad: evidence for the evolution of anti-predator behaviour in the wild. Proc. R. Soc. B Biol. Sci. 248, 117-122. doi: 10.1098/rspb.1992.0050

Merilä, J., Kruuk, L. E. B., and Sheldon, B. C. (2001). Cryptic evolution in a wild bird population. Nature 412, 76-79. doi: 10.1038/35083580

Moya-Laraño, J., Verdeny-Vilalta, O., Rowntree, J., Melguizo-Ruiz, N., Montserrat, M., and Laiolo, P. (2012). Climate change and eco-evolutionary dynamics in food webs. Adv. Ecol. Res. 47, 1-80. doi: 10.1016/B978-0-12-398315-2.00001-6

Northfield, T. D., and Ives, A. R. (2013). Coevolution and the effects of climate change on interacting species. PLoS Biol. 11:e1001685. doi: 10.1371/journal.pbio. 1001685

Novy, A., Flory, S. L., and Hartman, J. M. (2013). Evidence for rapid evolution of phenology in an invasive grass. J. Evol. Biol. 26, 443-450. doi: 10.1111/jeb.12047

O'Connor, M. I., Piehler, M. F., Leech, D. M., Anton, A., and Bruno, J. F. (2009). Warming and resource availability shift food web structure and metabolism. PLoS Biol. 7:e1000178. doi: 10.1371/journal.pbio.1000178

Olsen, E. M., Heino, M., Lilly, G. R., Morgan, M. J., Brattey, J., Ernande, B., et al. (2004). Maturation trends indicative of rapid evolution preceded the collapse of northern cod. Nature 428, 932-935. doi: 10.1038/nature02430

Ovaskainen, O., Skorokhodova, S., Yakovleva, M., Sukhov, A., Kutenkov, A., Kutenkova, N., et al. (2013). Community-level phenological response to climate change. Proc. Natl. Acad. Sci. U.S.A. 110, 13434-13439. doi: 10.1073/pnas.1305533110

Palkovacs, E. P., Dion, K. B., Post, D. M., and Caccone, A. (2008). Independent evolutionary origins of landlocked alewife populations and rapid parallel evolution of phenotypic traits. Mol. Ecol. 17, 582-597. doi: 10.1111/j.1365294X.2007.03593.x

Palkovacs, E. P., Marshall, M. C., Lamphere, B. A., Lynch, B. R., Weese, D. J., Fraser, D. F., et al. (2009). Experimental evaluation of evolution and coevolution as agents of ecosystem change in Trinidadian streams. Philos. Trans. R. Soc. B Biol. Sci. 364, 1617-1628. doi: 10.1098/rstb.2009.0016

Palkovacs, E. P., and Post, D. M. (2008). Eco-evolutionary interactions between predators and prey: can predator-induced changes to prey communities feed back to shape predator foraging traits? Evol. Ecol. Res. 10, 699-720.

Palkovacs, E. P., and Post, D. M. (2009). Experimental evidence that phenotypic divergence in predators drives community divergence in prey. Ecology 90, 300-305. doi: 10.1890/08-1673.1

Pelletier, F., Garant, D., and Hendry, A. P. (2009). Eco-evolutionary dynamics. Philos. Trans. R. Soc. B Biol. Sci. 364, 1483-1489. doi: 10.1098/rstb.2009.0027

Pimentel, D. (1961). Animal population regulation by the genetic feed-back mechanism. Am. Nat. 95, 65-79. doi: 10.1086/282160

Pimentel, D. (1968). Population regulation and genetic feedback. Science 159, 1432-1437. doi: 10.1126/science.159.3822.1432

Post, D. M., and Palkovacs, E. P. (2009). Eco-evolutionary feedbacks in community and ecosystem ecology: interactions between the ecological theatre and the evolutionary play. Philos. Trans. R. Soc. B Biol. Sci. 364, 1629-1640. doi: 10.1098/rstb.2009.0012

Post, D. M., Palkovacs, E. P., Schielke, E. G., and Dodson, S. I. (2008). Intraspecific variation in a predator affects community structure and cascading trophic interactions. Ecology 89, 2019-2032. doi: 10.1890/07-1216.1

Reznick, D., Butler, M. J., and Rodd, H. (2001). Life-history evolution in guppies. VII. The comparative ecology of high- and low-predation environments. Am. Nat. 157, 126-140. doi: 10.1086/318627

Reznick, D. N., Iv, M. J. B., Rodd, F. H., and Ross, P. (1996). Life-history evolution in guppies (Poecilia reticulata) 6. Differential mortality as a mechanism for natural selection. Evolution 50, 1651-1660. doi: 10.2307/2410901

Reznick, D. N., Shaw, F. H., Rodd, F. H., and Shaw, R. G. (1997). Evaluation of the rate of evolution in natural populations of guppies (Poecilia reticulata). Science 275, 1934-1937. doi: 10.1126/science.275.5308.1934

Sanchez, A., and Gore, J. (2013). Feedback between population and evolutionary dynamics determines the fate of social microbial populations. PLoS Biol. 11:e1001547. doi: 10.1371/journal.pbio.1001547

Schiffers, K., Bourne, E. C., Lavergne, S., Thuiller, W., and Travis, J. M. J. (2013). Limited evolutionary rescue of locally adapted populations facing climate change. Philos. Trans. R. Soc. B Biol. Sci. 368, 20120083. doi: 10.1098/rstb.2012.0083

Schoener, T. W. (2011). The newest synthesis: understanding the interplay of evolutionary and ecological dynamcis. Science 331, 426-429. doi: 10.1126/science. 1193954

Stenseth, N. C., and Mysterud, A. (2002). Climate, changing phenology, and other life history traits: nonlinearity and match-mismatch to the environment. Proc. Natl. Acad. Sci. U.S.A. 99, 13379-13381. doi: 10.1073/pnas.212 519399

Strauss, S. Y. (2014). Ecological and evolutionary responses in complex communities: implications for invasions and eco-evolutionary feedbacks. Oikos 123, 257-266. doi: 10.1111/j.1600-0706.2013.01093.x

Swain, D. P. (2011). Life-history evolution and elevated natural mortality in a population of Atlantic cod (Gadus morhua). Evol. Appl. 4, 18-29. doi: 10.1111/j.1752-4571.2010.00128.x

Terhorst, C. P., Miller, T. E., and Levitan, D. R. (2010). Evolution of prey in ecological time reduces the effect size of predators in experimental microcosms. Ecology 91, 629-636. doi: 10.1890/09-1481.1

Tessier, A. J., Leibold, M. A., and Tsao, J. (2000). A fundamental trade-off in resource exploitation by Daphnia and consequences to plankton communities. Ecology 81, 826-841. doi: 10.1890/00129658(2000)081[0826:AFTOIR]2.0.CO;2

Thériault, V., Moyer, G. R., Jackson, L. S., Blouin, M. S., and Banks, M. A. (2011). Reduced reproductive success of hatchery coho salmon in the wild: insights into most likely mechanisms. Mol. Ecol. 20, 1860-1869. doi: 10.1111/j.1365294X.2011.05058.x 
Thompson, J. N. (1998). Rapid evolution as an ecological process. Trends. Ecol. Evol. 13, 329-332. doi: 10.1016/S0169-5347(98)01378-0

Thompson, J. N. (2009). Which ecologically important traits are most likely to evolve rapidly? Oikos 118, 1281-1283. doi: 10.1111/j.1600-0706.2009.17835.x

Tien, R. J., and Ellner, S. P. (2012). Variable cost of prey defense and coevolution in predator-prey systems. Ecol. Monogr. 82, 491-504. doi: 10.1890/11-2168.1

Tirok, K., Bauer, B., Wirtz, K., and Gaedke, U. (2011). Predator-prey dynamics driven by feedback between functionally diverse trophic levels. PLoS ONE 6:e27357. doi: 10.1371/journal.pone.0027357

Tirok, K., and Gaedke, U. (2010). Internally driven alternation of functional traits in a multispecies predator-prey system. Ecology 91, 1748-1762. doi: 10.1890/091052.1

Turcotte, M. M., Reznick, D. N., and Hare, J. D. (2011). Experimental assessment of the impact of rapid evolution on population dynamics. Evol. Ecol. Res. 13, $113-131$.

Turley, N. E., Odell, W. C., Schaefer, H., Everwand, G., Crawley, M. J., and Johnson, M. T. (2013). Contemporary evolution of plant growth rate following experimental removal of herbivores. Am. Nat. 181, S21-S34. doi: 10.1086/668075

Urban, M. C., Leibold, M. A., Amarasekare, P., de Meester, L., Gomulkiewicz, R., Hochberg, M. E., et al. (2008). The evolutionary ecology of metacommunities. Trends. Ecol. Evol. 23, 311-317. doi: 10.1016/j.tree.2008.02.007

Van der Putten, W. H., Macel, M., and Visser, M. E. (2010). Predicting species distribution and abundance responses to climate change: why it is essential to include biotic interactions across trophic levels. Philos. Trans. R. Soc. B Boil. Sci. 365, 2025-2034. doi: 10.1098/rstb.2010.0037

Walsh, M. R. (2012). The evolutionary consequences of indirect effects. Trends. Ecol. Evol. 28, 23-29. doi: 10.1016/j.tree.2012.08.006

Walsh, M. R., deLong, J. P., Hanley, T. C., and Post, D. M. (2012). A cascade of evolutionary change alters consumer-resource dynamics and ecosystem function. Proc. R. Soc. B. 279, 3184-3192. doi: 10.1098/rspb.2012.0496

Walsh, M. R., and Post, D. M. (2011). Interpopulation variation in a fish predator drives evolutionary divergence in prey in lakes. Proc. R. Soc. B. 278, 2628-2637. doi: $10.1098 /$ rspb.2010.2634

Wirtz, K. W. (2011). Non-uniform scaling in phytoplankton growth rate due to intracellular light and CO2 decline. J. Plankton. Res. 33, 1325-1341. doi: 10.1093/plankt/fbr021
Woodward, G., Perkins, D. M., and Brown, L. E. (2010). Climate change and freshwater ecosystems: impacts across multiple levels of organization. Philos. Trans. R. Soc. 365, 2093-2106. doi: 10.1098/rstb.2010.0055

Yamamichi, M., Yoshida, T., and Sasaki, A. (2011). Comparing the effects of rapid evolution and phenotypic plasticity on predator-prey dynamics. Am. Nat. 178, 287-304. doi: $10.1086 / 661241$

Yang, B., Ge, F., Ouyang, F., and Parajulee, M. (2012). Intra-species mixture alters pest and disease severity in cotton. Environ. Entomol. 41, 1029-1036. doi: $10.1603 /$ EN11182

Yoshida, T., Ellner, S. P., Jones, L. E., Bohannan, B. J. M., Lenski, R. E., and Hairston, N. G. Jr. (2007). Cryptic population dynamics: rapid evolution masks trophic interactions. PLoS Biol. 5:e235. doi: 10.1371/journal.pbio.0050235

Yoshida, T., Hairston, N. G., and Ellner, S. P. (2004). Evolutionary tradeoff between defence against grazing and competitive ability in a simple unicellular alga, Chlorella vulgaris. Proc. Boil. Sci. 271, 1947-1953. doi: $10.1098 / \mathrm{rspb} .2004 .2818$

Yoshida, T., Jones, L. E., Ellner, S. P., Fussmann, G. F., and Hairston, N. G. (2003). Rapid evolution drives ecological dynamics in a predator-prey system. Nature 424, 303-306. doi: 10.1038/nature01767

Conflict of Interest Statement: The authors declare that the research was conducted in the absence of any commercial or financial relationships that could be construed as a potential conflict of interest.

Received: 14 March 2014; accepted: 28 April 2014; published online: 20 May 2014. Citation: Koch H, Frickel J, Valiadi M and Becks L (2014) Why rapid, adaptive evolution matters for community dynamics. Front. Ecol. Evol. 2:17. doi: 10.3389/fevo. 2014.00017

This article was submitted to Population Dynamics, a section of the journal Frontiers in Ecology and Evolution.

Copyright (1) 2014 Koch, Frickel, Valiadi and Becks. This is an open-access article distributed under the terms of the Creative Commons Attribution License (CC BY). The use, distribution or reproduction in other forums is permitted, provided the original author(s) or licensor are credited and that the original publication in this journal is cited, in accordance with accepted academic practice. No use, distribution or reproduction is permitted which does not comply with these terms. 